\title{
BMJ Open Characteristics of low-tier female sex workers who engage in commercial sex with old male clients in Zhejiang province, China: a cross-sectional study
}

\author{
Tingting Jiang, Xiaohong Pan (D), Qiaoqin Ma (D) , Jianmin Jiang, Lin Chen (D), \\ Hui Wang, Xin Zhou, Wanjun Chen
}

To cite: Jiang T, Pan X, Ma Q, et al. Characteristics of lowtier female sex workers who engage in commercial sex with old male clients in Zhejiang province, China: a crosssectional study. BMJ Open 2021;11:e049410. doi:10.1136/ bmjopen-2021-049410

- Prepublication history for this paper is available online. To view these files, please visit the journal online (http://dx.doi. org/10.1136/bmjopen-2021049410).

Received 26 January 2021 Accepted 26 October 2021

Check for updates

(C) Author(s) (or their employer(s)) 2021. Re-use permitted under CC BY-NC. No commercial re-use. See rights and permissions. Published by BMJ.

Department of HIV/STD prevention and control, Zhejiang Provincial Center for Disease

Control and Prevention,

Hangzhou, Zhejiang, China

Correspondence to Dr Qiaoqin Ma; qqma@cdc.zj.cn and

Dr Jianmin Jiang;

jmjiang@cdc.zj.cn

\section{ABSTRACT}

Objectives To characterise low-tier female sex workers (FSWs) who engage in commercial sex with old male clients (OMCs).

Design Cross-sectional study.

Setting Twenty-one counties in Zhejiang province, China. Participants A total of 2647 low-tier FSWs who participated in our survey from September to November 2013 , and responded to the question regarding whether they engaged in commercial sex with OMCs during the previous month.

Main outcome measures Data on sociodemographic characteristics, sexual behaviours, risk perception of HIV/sexually transmitted infection (STI), ever exposure to an HIV prevention service and degree of self-efficacy regarding condom use were collected via a face-to-face questionnaire administered by trained interviewers. Results Of the 2647 participants, 1165 (44.0\%) had engaged in commercial sex with OMCs in the previous month. Low-tier FSWs working out of roadside shops, those who had engaged in sex work for longer, those with a larger number of clients, those who had engaged in anal or oral sex during the previous month, those currently using contraception measures, those who had STI symptoms and those who had been exposed to HIV prevention services during the previous 6 months were more likely to engage in commercial sex with OMCs. FSWs with a high level of education; those working out of small venues other than streets, hair salons and roadside shops; those who charged more for commercial sex; those who had sex with young clients during the previous month and those who had seen a doctor during the previous 6 months were less likely to engage in commercial sex with OMCs. Conclusions Low-tier FSWs who engaged in commercial sex with OMCs reported more risky behaviours than those who did not engage in this behaviour. Attention should be paid to these behaviours in future interventions targeting low-tier FSWs.

\section{INTRODUCTION}

Female sex workers (FSWs) are at higher risk of HIV infection than the general female population, and a systematic review and meta-analysis indicated that FSWs were 13.5fold more likely to be living with HIV than the
Strengths and limitations of this study

- This is the first study of the characteristics of lowtier female sex workers (FSWs) who engaged in commercial sex with old male clients in China.

- This large study targeted all low-tier FSWs in 21 counties of Zhejiang province.

- Information bias, particularly related to the sexual behaviour questions, may have been present due to the sensitivity of such behaviour and the illegality and stigma of sex work in China.

- The short-term, cross-sectional design and nonrandom sampling method may limit the generalisability of our findings to low-tier FSWs in other regions of China.

general female population in low-income and middle-income countries. ${ }^{1}$ Another metaanalysis reported a global HIV prevalence among FSWs of $10.4 \%$, and an increased HIV burden among FSWs compared with adult women in all regions, although there is large variability in HIV prevalence among FSWs across regions. ${ }^{2}$ FSWs are considered an important bridge population for the transmission of HIV and sexually transmitted infections (STIs) between high-risk clients and noncommercial partners, such as husbands and regular boyfriends. ${ }^{34}$

FSWs in China are classified as high, middle or low tier according to the venues they work in. Low-tier FSWs are defined as those who work in smaller and hidden venues, such as hair salons, rental accommodations, small hotels and so on, or on the street. ${ }^{5-9}$ Low-tier FSWs typically have lower living standards and are older, less educated, and married, separated or divorced. ${ }^{9} 10$ These sociodemographic characteristics may be related to a higher rate of condomless $\operatorname{sex}^{9}{ }^{10}$ and lower use of HIV prevention services. ${ }^{11}$ Low-tier FSWs have less understanding of HIV and 
STI than middle-tier and high-tier FSWs, and do not tend to use condoms regularly. ${ }^{6}{ }^{12} 13$ Low-tier FSWs who use condoms infrequently can attract more clients and earn extra money, and this economic incentive limits the likelihood of engaging in safer sex. ${ }^{14}$ These factors result in higher rates of HIV and STIs among low-tier than hightier and middle-tier FSWs. ${ }^{6} 8$ Two cross-sectional studies revealed HIV and syphilis prevalences among low-tier FSWs of $2 \%-5 \%$ and $11 \%-15 \%$, respectively. ${ }^{15}$ In a meta-analysis, the HIV prevalence among low-tier FSWs was $1.37 \%$, whereas that among middle-tier and high-tier FSWs was $0.28 \%$ and $0.07 \%$, respectively. ${ }^{16}$

The number and proportion of older people with HIV have increased rapidly in recent years, both internationally and domestically. According to a report from the Joint United Nation Programme on HIV/AIDS, the number of HIV-infected people over 50 years of age was approximately 5.8 million in 2015, which accounted for $15.8 \%$ of the total of 36.7 million HIV infections. ${ }^{17}$ In Canada, the proportion of newly diagnosed HIV cases among those $\geq 50$ years of age increased from $15.1 \%$ to $22.8 \%$ between 2008 and $2017 .^{18}$

In China, the number of older people diagnosed with HIV cases has also increased, and the number of newly diagnosed patients aged $\geq 65$ years in 2016 accounted for $10.4 \%$ of the newly diagnosed cases in that year. ${ }^{19}$ Most newly diagnosed persons aged $\geq 65$ years are male; the male-to-female ratio in that group is 5-1. Commercial sex is the key transmission route for HIV in older males, and $70 \%-90 \%$ of older males living with HIV admit to participating in commercial sex. ${ }^{20}$ In Zhejiang province, the number of newly diagnosed HIV cases aged $\geq 60$ years has increased rapidly, with an annual average increase of $15.6 \%$ from 2015 to $2018 ; 80.6 \%$ of newly diagnosed cases during this period were male, and two-thirds of them reported experiencing heterosexual commercial sex. ${ }^{21}$

Previous research in China has documented the characteristics of men who had sex with low-tier FSWs. Male clients who visit low-tier FSWs are more likely to practice unprotected sex than those who visit high-tier FSWs, and have low risk awareness and knowledge of HIV/STIs. ${ }^{22}$ Old male clients (OMCs) were reported to have high HIV and syphilis infection rates, and most of them visited lowtier venues and used condoms very infrequently while having sex with low-tier FSWs. ${ }^{23}{ }^{24}$ Older clients tend to use lower-tier sex venues. ${ }^{24}$ Older males infected with HIV through commercial sex reported that the sex transactions usually occurred in small venues, such as rental accommodations or small hotels, with the price per sex act being less than 50 Yuan (approximately US $\$ 7$ ) in Zhejiang province. ${ }^{21}$

Low-tier FSWs and older clients have a mutual influence on each other in terms of HIV/STI infection. However, there has been no report of the characteristics of low-tier FSWs who have sex with OMCs in China. We explored the characteristics of low-tier FSWs who engage in this behaviour, to promote the development of comprehensive HIV prevention programmes targeting low-tier FSWs.

\section{METHODS}

\section{Study design}

This was a cross-sectional study of low-tier FSWs who engaged in commercial sex with OMCs in Zhejiang province, China.

\section{Study area}

The study area covered 21 counties in Zhejiang province. Zhejiang, which has a relatively developed economy, is located on the east coast of China and has a population of 55.4 million people; it includes 90 counties in 11 prefectures. ${ }^{25}$ Of them, 22 counties implemented the AIDS Care Project in 2013. The AIDS Care Project was a pilot programme initiated by the National Ministry of Health and Provincial Bureau of Health, to support and promote HIV prevention practices and policies. Of the 22 counties, 1 did not participate in the study because no low-tier FSWs were identified therein; the remaining 21 counties were distributed across all 11 prefectures of the province.

\section{Study period}

September to November 2013.

\section{Study participants}

FSWs were eligible to participate if they were currently engaging in commercial sex on the street and/or at small venues, including hair salons, roadside shops and other venues with fewer than nine FSWs. In total, 2648 low-tier FSWs participated in the study. Of them, 2647 FSWs who responded to the question regarding whether they engaged in commercial sex with OMCs during the previous month were included in the analysis.

\section{Study process}

The questionnaire was developed based on instruments used for HIV sentinel surveillance of FSWs in Zhejiang, and on comprehensive reviews of international and Chinese studies on low-tier FSWs. The questionnaire was finalised based on discussions within the research team, consultations with the staff of local Centers for Disease Control and Prevention (CDCs) who conducted outreach interventions among FSWs in the counties studied, and two pilot surveys of low-tier FSWs in two counties.

A pilot survey to determine the location of low-tier FSWs in the 21 counties was conducted, and a plan for the field survey was developed. The staff of local CDCs who conducted behavioural interventions for FSWS, and were familiar with the FSW communities in the study areas, were trained by the research team and then reached out to recruit participants from low-tier venues. Face-to-face interviews were then conducted using a structured questionnaire. All data were anonymised. The interview was conducted in a private and quiet space within the venues. The study's purpose, method and confidentiality policy were explained verbally. All participating FSWs provided informed oral consent. Consent to participate in the study was indicated by ticking the box following the Chinese word 'agree' at the beginning of each questionnaire. 


\section{Measures}

Self-reported commercial sex with OMCs during the previous month was the dependent variable in the analysis. The participants were divided into those who did and those who did not engage in commercial sex with OMCs.

The independent variables included sociodemographic characteristics (age, current residence, educational level, marital status, income per month and location of sampling), and behavioural and psychological characteristics (duration of practising commercial sex, number of clients, having anal and oral sex with clients, having young-aged and middle-aged clients, average fee per sex act, condom use during the previous month, current use of contraception, presence of STI symptoms, seen by a doctor (and diagnosed with an STI among those who had seen a doctor), exposure to an HIV prevention service during the previous 6 months, risk perception of HIV and STI infection, and degree of self-efficacy regarding condom use).

The participants estimated the ages of their clients during the previous month. Current use of contraception refers to the use of intrauterine devices, tubal ligation or the Norplant method. STI symptoms include painful urination or a burning sensation, abnormal genital secretions, genital skin damage or hyperplasia and anal ulcers. HIV prevention service refers to any intervention involving the distribution of educational material and/ or condoms, face-to-face education delivered by medical staff, peer education, etc.

The scale measuring self-efficacy regarding condom use consisted of three questions pertaining to whether an FSW could persuade a reluctant client to use a condom, whether she could refuse sex when a client refused to use a condom, and whether she could insist on using a condom with every client. The response options were 'I can,' 'I can't' and 'I'm not sure'. 'I can' responses were assigned 1 point, and 'I can't' and 'I'm not sure' responses were assigned 0 points. Cronbach's alpha was computed to determine the internal consistency of the scale; the value was 0.913. The FSWs were categorised into three self-efficacy groups; score of 3, high level of self-efficacy; score of 1-2, intermediate level of self-efficacy; and score of 0 , low level of self-efficacy.

\section{Patient and public involvement}

No patients were involved in the questionnaire survey. The questionnaire survey involved face-to-face interviews conducted by trained staff of the 21 local CDCs in the study area.

\section{Statistical analysis}

Data were analysed using SPSS for Windows software V.17.0; SPSS). Factors associated with engagement by lowtier FSWs in commercial sex with OMCs were identified by univariate analysis. Variables significant in univariate analyses were included in a multivariate logistic regression model. ORs and $95 \%$ CIs were used to quantify the association between the dependent variable and independent variables. A $\mathrm{p}<0.05$ was considered indicative of statistical significance in the univariate and multivariate analyses.

\section{RESULTS}

\section{Sociodemographic characteristics}

Of the 2647 FSWs, 1165 (44.0\%) had commercial sex with OMCs during the previous month, and 1482 (56.0\%) did not. Of the FSWs, $40.5 \%$ were aged $26-35$ years (table 1 ). Overall, $78.2 \%$ were from provinces other than Zhejiang. In terms of education, $53.1 \%$ of the FSWs had received a junior high school education; $62.4 \%$ were married or had cohabited with someone. In total, $40.3 \%$ of the FSWs had an income of $¥ 3000$ - $¥ 4000$ ( $¥ 1=$ US $\$ 0.143$ ) per month. Most of the FSWs worked in hair salons $(63.5 \%)$.

\section{Sociodemographic correlates of commercial sex with OMCs among low-tier FSWs}

Univariate analyses indicated that residence and income per month were not associated with self-reported commercial sex with OMCs (table 1). FSWs who had a junior high or at least high school education, and those who worked in hair salons and at locations other than the streets, hair salons or roadside shops, were less likely to engage in commercial sex with OMCs. FSWs aged 25-35 years or $>35$ years, those who were married or had cohabited with someone, and those who were widowed or divorced were more likely to engage in commercial sex with OMCs.

\section{Behavioural and psychological correlates of commercial sex with OMCs among low-tier FSWs}

Univariate analyses indicated that FSWs who had commercial sex with young men, those who charged an average price of $¥ 51-¥ 100$ or $>¥ 100$ per sex act, those who always/ often used condoms, and those who had seen a doctor during the previous 6 months were less likely to engage in commercial sex with OMCs during the previous month (table 2).

FSWs who had engaged in commercial sex for 13-24 or $>24$ months, those who had experienced commercial sex with 16-30 or $>30$ clients, those who had experienced anal sex with clients, those who had experienced oral sex, those who used contraception at present, those who had shown STI symptoms during the previous 6 months, those who were diagnosed with an STI, those who were exposed to an HIV prevention service during the previous half year, those who believed that they were likely to contract HIV, and those who believed that they were likely to contract STIs were more likely to engage in commercial sex with OMCs during the previous month (table 2).

Middle-aged clients during the previous month and self-efficacy for condom use were not associated with commercial sex with OMCs.

\section{Multivariate analysis}

After controlling for possible confounding variables, the multivariate analysis revealed that FSWs with at least a junior high school education (OR $0.78,95 \%$ CI 0.63 to 0.95 ) or 
Table 1 Correlations of sociodemographic characteristics with commercial sex with old male clients (OMCs) among low-tier FSWs ( $=2647)$

\begin{tabular}{|c|c|c|c|c|}
\hline Variable & Total (\%) & OMCs (\%) & Crude OR $(95 \% \mathrm{Cl})^{*}$ & $P$ value \\
\hline \multicolumn{5}{|l|}{ Age (years) } \\
\hline$\leq 25$ & $843(31.8)$ & $300(35.6)$ & 1 & \\
\hline $26-35$ & $1071(40.5)$ & $433(40.4)$ & 1.23 (1.02 to 1.48$)$ & 0.031 \\
\hline$\geq 36$ & $726(27.4)$ & $432(59.5)$ & 2.67 (2.17 to 3.26$)$ & 0.000 \\
\hline \multicolumn{5}{|l|}{ Residence } \\
\hline Local area & $270(10.2)$ & $126(46.7)$ & 1 & \\
\hline Other area in this province & 307 (11.6) & $134(43.6)$ & 0.89 (0.64 to 1.23) & 0.467 \\
\hline Other province & $2070(78.2)$ & $905(43.7)$ & 0.89 (0.69 to 1.15$)$ & 0.359 \\
\hline \multicolumn{5}{|l|}{ Education } \\
\hline Primary school or below & $974(36.8)$ & $507(52.1)$ & 1 & \\
\hline Junior high school & $1405(53.1)$ & $573(40.8)$ & 0.63 (0.54 to 0.75$)$ & 0.000 \\
\hline High school or above & $262(9.9)$ & $83(31.7)$ & 0.43 (0.32 to 0.57$)$ & 0.000 \\
\hline \multicolumn{5}{|l|}{ Marital status } \\
\hline Unmarried & $762(28.8)$ & 292 (38.3) & 1 & \\
\hline Married/cohabit & $1652(62.4)$ & $751(45.5)$ & 1.34 (1.13 to 1.60$)$ & 0.001 \\
\hline Widowed/divorced & $229(8.7)$ & $121(52.8)$ & 1.80 (1.34 to 2.43$)$ & 0.000 \\
\hline \multicolumn{5}{|l|}{ Income per month ( $¥)$} \\
\hline$<¥ 3000$ & $746(28.2)$ & $333(44.6)$ & 1 & \\
\hline$¥ 3000-¥ 4000$ & $1068(40.3)$ & $479(44.9)$ & 1.01 (0.84 to 1.22$)$ & 0.929 \\
\hline$>¥ 4000$ & 748 (28.3) & $326(43.6)$ & 0.96 (0.78 to 1.18$)$ & 0.681 \\
\hline \multicolumn{5}{|l|}{ Location of sampling } \\
\hline Street & $413(15.6)$ & $224(54.2)$ & 1 & \\
\hline Hair salon & $1682(63.5)$ & $714(42.4)$ & 0.62 (0.50 to 0.77$)$ & 0.000 \\
\hline Roadside shop & $276(10.4)$ & $163(59.1)$ & 1.22 (0.89 to 1.66$)$ & 0.212 \\
\hline Other & $271(10.2)$ & $64(23.6)$ & $0.26(0.19$ to 0.37$)$ & 0.000 \\
\hline
\end{tabular}

${ }^{*}$ The percentages may not sum to $100 \%$ because of missing data. FSWs, female sex workers.

at least a high school education (OR $0.61,95 \%$ CI 0.44 to $0.86)$; those who worked at locations other than the streets, hair salons and roadside shops (OR $0.53,95 \%$ CI 0.35 to 0.80 ); those who charged an average of $¥ 51-¥ 100$ (OR 0.58 , $95 \%$ CI 0.44 to 0.76 ) or $>¥ 100$ (OR $0.33,95 \%$ CI 0.25 to 0.45 ) per sex act; those who had engaged in commercial sex with young clients (OR $0.72,95 \%$ CI 0.59 to 0.89 ); and those who had seen a doctor (OR $0.61,95 \%$ CI 0.49 to 0.76 ) were less likely to engage in commercial sex with OMCs (table 3).

FSWs at roadside shops (OR 1.49, 95\% CI 1.03 to 2.15), those who had engaged in commercial sex for 13-24 months (OR 1.33, 95\% CI 1.02 to 1.74 ) or $>24$ months (OR 2.22, $95 \%$ CI 1.79 to 2.76 ), those who had 16-30 sexual clients (OR 1.99, 95\% CI 1.59 to 2.50 ) and $>30$ sexual clients (OR $2.14,95 \%$ CI 1.69 to 2.70 ), those who performed anal sex (OR 3.02, 95\% CI 1.88 to 4.87 ), those who performed oral sex (OR 2.64, 95\% CI 2.08 to 3.35), those who used contraception (OR 1.95, 95\% CI 1.58 to 2.39), those who reported STI symptoms (OR 1.36, 95\% CI 1.02 to 1.82 ) and those ever exposed to HIV prevention services (OR 2.00, 95\% CI 1.51 to 2.64) were more likely to engage in commercial sex with OMCs (table 3).

\section{DISCUSSION}

This study is the first to examine the characteristics of lowtier FSWs who engaged in commercial sex with OMCs in China. Chinese studies have revealed that low-tier FSWs have a high rate of unprotected sex ${ }^{91012}$ and high prevalence of HIV/STI infection. ${ }^{681516}$ We found that $44 \%$ of our low-tier FSWs had commercial sex with OMCs during the previous month, and that they engaged in more risky behaviours related to HIV/STI infection than other lowtier FSWs who did not engage in sex with OMCs. These findings enhance our knowledge of low-tier FSWs in China, and indicate that the risk of HIV infection/STI varies among low-tier FSWs.

Low-tier FSWs have a low socioeconomic status. ${ }^{9}{ }^{10}$ The low-tier FSWs who had commercial sex with OMCs in this study tended to have a low level of education; such 
Table 2 Behavioural and psychological correlates of commercial sex with old male clients (OMCs) among low-tier FSWs $(\mathrm{N}=2647)$

\begin{tabular}{|ccccc}
\hline Variable & OMCs (\%) & Non-OMCs (\%) & Crude OR (95\% Cl) & P value \\
\hline Duration of practising commercial sex (months) & & & \\
\hline $1-12$ & $303(26.0)$ & $766(51.7)$ & 1 & 0.000 \\
$13-24$ & $183(15.7)$ & $245(16.5)$ & $1.89(1.50$ to 2.38$)$ & 0.000 \\
\hline 24 & $679(58.3)$ & $468(31.6)$ & $3.67(3.07$ to 4.38$)$ &
\end{tabular}

No of clients during the previous month

$\begin{array}{lllll}<16 & 273(23.4) & 701(47.3) & 1 & \\ 16-30 & 435(37.3) & 420(28.3) & 2.66(2.19 \text { to } 3.13) & 0.000 \\ >30 & 454(39.0) & 346(23.3) & 3.37(2.77 \text { to } 4.11) & 0.000\end{array}$

Anal sex during the previous month

$\begin{array}{lcccc}\text { No } & 1063(91.2) & 1447(97.6) & 1 & \\ \text { Yes } & 101(8.7) & 32(2.2) & 4.30(2.86 \text { to } 6.44) & 0.000\end{array}$

Oral sex during the previous month

$\begin{array}{llrll}\text { No } & 784(67.3) & 1280(86.4) & 1 & \\ \text { Yes } & 380(32.6) & 199(13.4) & 3.12(2.57 \text { to } 3.78) & 0.000\end{array}$

Young client during the previous month

$\begin{array}{lllll}\text { No } & 834(71.6) & 917(61.9) & 1 & \\ \text { Yes } & 331(28.4) & 565(38.1) & 0.64(0.55 \text { to } 0.76) & 0.000\end{array}$

Middle-aged client during the previous month

\begin{tabular}{|c|c|c|c|c|}
\hline No & $64(5.5)$ & $59(4.0)$ & 1 & \\
\hline Yes & $1101(94.5)$ & $1423(96.0)$ & 0.71 (0.50 to 1.03$)$ & 0.068 \\
\hline \multicolumn{5}{|c|}{ Average fee per sex act $(¥)$} \\
\hline$\leq ¥ 50$ & $285(24.5)$ & $158(10.7)$ & 1 & \\
\hline$¥ 51-¥ 100$ & $549(47.1)$ & $573(38.7)$ & 0.53 (0.42 to 0.67$)$ & 0.000 \\
\hline$>¥ 100$ & $329(28.2)$ & $747(50.4)$ & 0.24 (0.19 to 0.31$)$ & 0.000 \\
\hline \multicolumn{5}{|c|}{ Condom use during the previous month } \\
\hline Never/rarely & $170(14.6)$ & $168(11.3)$ & 1 & \\
\hline Sometimes & $201(17.3)$ & $188(12.7)$ & $1.06(0.79$ to 1.41$)$ & 0.711 \\
\hline Always/often & $793(68.1)$ & $1126(76.0)$ & 0.70 (0.55 to 0.88$)$ & 0.002 \\
\hline \multicolumn{5}{|c|}{ Currently using contraception } \\
\hline No & $431(37.0)$ & $874(59.0)$ & 1 & \\
\hline Yes & $734(63.0)$ & $605(40.8)$ & 2.46 (2.10 to 2.88$)$ & 0.000 \\
\hline \multicolumn{5}{|c|}{ STI symptoms during the previous 6 months } \\
\hline No & $987(84.7)$ & $1333(89.9)$ & 1 & \\
\hline Yes & $176(15.1)$ & $142(9.6)$ & 1.67 (1.32 to 2.12$)$ & 0.000 \\
\hline \multicolumn{5}{|c|}{ Seen a doctor during the previous 6 months } \\
\hline No & $867(74.4)$ & $1009(68.14)$ & 1 & \\
\hline Yes & $298(25.6)$ & $472(31.8)$ & 0.74 (0.62 to 0.87$)$ & 0.000 \\
\hline \multicolumn{5}{|c|}{ STI diagnosed during the previous half year $(n=770)^{*}$} \\
\hline No & $216(72.5)$ & $415(87.9)$ & 1 & \\
\hline Yes & $82(27.5)$ & $56(11.9)$ & 2.81 (1.93 to 4.10$)$ & 0.000 \\
\hline \multicolumn{5}{|c|}{ Exposure to HIV prevention service during the previous 6 months } \\
\hline No & $126(10.8)$ & $273(18.4)$ & 1 & \\
\hline Yes & $1039(89.2)$ & $1209(81.6)$ & 1.86 (1.48 to 2.34$)$ & 0.000 \\
\hline
\end{tabular}


Table 2 Continued

\begin{tabular}{|c|c|c|c|c|}
\hline Variable & OMCs (\%) & Non-OMCs (\%) & Crude OR (95\% CI) & $P$ value \\
\hline Impossible/unsure & $880(75.5)$ & 1174 (79.2) & 1 & \\
\hline Possible & $285(24.5)$ & $306(20.6)$ & 1.24 (1.03 to 1.49$)$ & 0.020 \\
\hline \multicolumn{5}{|c|}{ Risk perception of STI infection } \\
\hline Impossible/unsure & $726(62.3)$ & 1061 (71.6) & 1 & \\
\hline Possible & 439 (37.3) & $421(28.4)$ & 1.52 (1.29 to 1.80$)$ & 0.000 \\
\hline 0 & $463(39.7)$ & $565(38.1)$ & 1 & \\
\hline $1-2$ & $144(12.4)$ & $214(14.4)$ & $0.82(0.64$ to 1.05$)$ & 0.114 \\
\hline 3 & $558(47.9)$ & $703(47.4)$ & $0.97(0.82$ to 1.14$)$ & 0.706 \\
\hline
\end{tabular}

${ }^{*}$ This variable was not included in the multivariate analysis.

FSWs, female sex workers; STI, sexually transmitted infection.

FSWs also tend to have lower HIV-related knowledge, ${ }^{12}$ and lower rates of condom use and participation in HIV testing, ${ }^{96}$ which increases their risk of HIV infection/ STIs.

A long duration of practising commercial sex by the lowtier FSWs was associated with a higher likelihood of having sex with OMCs specifically. In addition, the competitiveness of FSWs with longer careers as sex workers might be lower, motivating them to have sex with OMCs. In a Chinese study, older FSWs had fewer clients and made less money than younger FSWs working in the same venue. ${ }^{27}$ A longer duration of participation in commercial sex is a risk factor for STIs ${ }^{28}$ and HIV infection. ${ }^{2329}$ The relationship between a long duration of practising sex work and engaging in sex with OMCs should be considered when implement HIV-related interventions for low-tier FSWs.

Low-tier FSWs became sex workers mainly because of economic reasons, and earn less money per sex act than middle-tier and high-tier FSWs. ${ }^{27} 3031$ Our study revealed that the higher the fee per sex act, the less likely low-tier FSWs were to engage in commercial sex with OMCs. Also, the low-tier FSWs who had commercial sex with OMCs had more clients during the previous month than those who did not, implying that the former group of low-tier FSWs have less competition for sex services than other low-tier FSWs. Having multiple sexual partners is a risk factor for HIV infection for low-tier FSWs; however, condom use prevalence was not higher in this group in the multivariate analysis, so they are vulnerable to HIV infection and STIs.

In this study, the low-tier FSWs who had commercial sex with OMCs were less likely to have sex with young clients, suggesting that they are less attractive to young clients and so rely on elderly individuals for sex transactions. This group of FSWs tended to work on the streets and in roadside shops; in addition, they had a low level of education, implying a low socioeconomic status. OMCs usually seek out low-tier FSWs for commercial sex, ${ }^{32}$ and streetbased FSWs have lower educational levels and charge less than venue-based FSWs. ${ }^{33}$ OMCs reportedly have higher rates of HIV and syphilis infections than the general male population of China. ${ }^{32}$ Street-based FSWs use condoms at a very low rate and have a high prevalence of STIs ${ }^{33}$; moreover, most older male HIV cases contracted the disease via commercial sex with FSWs at small venues. ${ }^{21}$ Precautionary measures should be taken because lowertier FSWs and OMCs can transmit HIV and STIs to each other, and the spouses and regular partners of OMCs are thus at risk for STI/HIV infection. In China, most older HIV-positive women were infected by their male spouse. ${ }^{20}$

The risk of HIV acquisition and transmission is markedly higher via receptive anal than vaginal sex. ${ }^{34-36}$ In this study, $8.7 \%$ of the respondents who had sex with OMCs practiced anal sex. FSWs who had sex with OMCs were more likely to have anal sex. Most low-tier FSWs do not understand the risk of HIV and STI transmission posed by anal sex. ${ }^{37}$ Similarly, this group of FSWs are more likely to have oral sex. Although oral sex carries a low risk of STI/ HIV infection, those engaging in it show risky behaviours associated with STIs/HIV infection, such as multiple partners and low levels of condom use, according to Chinese studies. ${ }^{38} 39$ Therefore, the roles of anal and oral intercourse in HIV/STI transmission should not be ignored, because these behaviours were reported at high rates by FSWs having sex with OMCs.

The low-tier FSWs in this study who had commercial sex with OMCs were more likely to use contraception. Low-tier FSWs use contraception with long-lasting effects to avoid unwanted pregnancies ${ }^{40}$ and loss of clients. ${ }^{61}$ Therefore, it is critical to address shortcomings in contraceptive measures to prevent HIV infection and STIs in low-tier FSWS.

Around $40 \%$ of the FSWs in this study who had commercial sex with OMCs had a score of zero for condom-use self-efficacy, and the rate of consistent and frequent use of condoms was $<70 \%$. Other studies revealed that low-tier FSWs had high rates of unprotected sex, and that HIV knowledge, risk perception and venue type were associated with unprotected sex among low-tier FSWs. ${ }^{5} 2733$ Economic pressures limit the likelihood of low-tier FSWs 
Table 3 Multivariate analysis of commercial sex with old male clients among low-tier FSWs

\begin{tabular}{|c|c|c|}
\hline Variable & $\begin{array}{l}\text { Adjusted OR } \\
(95 \% \mathrm{Cl})\end{array}$ & $P$ value \\
\hline \multicolumn{3}{|l|}{ Education } \\
\hline \multicolumn{3}{|l|}{ Primary school and below 1} \\
\hline Junior high school & 0.78 (0.63 to 0.95$)$ & 0.015 \\
\hline High school and above & 0.61 (0.44 to 0.86$)$ & 0.005 \\
\hline \multicolumn{3}{|l|}{ Location of sampling } \\
\hline Street & 1 & \\
\hline Hair salon & $1.07(0.81$ to 1.41$)$ & 0.635 \\
\hline Roadside shop & 1.49 (1.03 to 2.15$)$ & 0.034 \\
\hline Other & $0.53(0.35$ to 0.80$)$ & 0.003 \\
\hline
\end{tabular}

Duration of practising commercial sex

\begin{tabular}{|c|c|c|}
\hline $1-12$ months & 1 & \\
\hline 13-24 months & $1.33(1.02$ to 1.74$)$ & 0.036 \\
\hline$>24$ months & $2.22(1.79$ to 2.76$)$ & 0.000 \\
\hline \multicolumn{3}{|c|}{ No of clients during the previous month } \\
\hline$<16$ & 1 & \\
\hline $16-30$ & 1.99 (1.59 to 2.50$)$ & 0.000 \\
\hline$>30$ & 2.14 (1.69 to 2.70$)$ & 0.000 \\
\hline
\end{tabular}

Average fee per sex act during the previous month ( $¥)$

$\begin{array}{lll}\leq 50 & 1 & \\ 51-100 & 0.58(0.44 \text { to } 0.76) & 0.000 \\ >100 & 0.33(0.25 \text { to } 0.45) & 0.000\end{array}$

Anal sex during the previous month

$\begin{array}{ccc}\text { No } & 1 & \\ \text { Yes } & 3.02(1.88 \text { to } 4.87) & 0.000 \\ \text { Oral sex during the previous month } & \\ \text { No } & 1 \\ \text { Yes } & 2.64(2.08 \text { to } 3.35) & 0.000\end{array}$

Young client during the previous month

\begin{tabular}{lcc} 
No & 1 & \\
Yes & $0.72(0.59$ to 0.89$)$ & 0.002 \\
\hline Currently using contraception & \\
No & 1 & \\
Yes & 1.95 (1.58 to 2.39) & 0.000 \\
STI symptoms during the 6 previous 6 months & \\
No & 1 & \\
Yes & $1.36(1.01$ to 1.82$)$ & 0.043 \\
Seen a doctor during the previous 6 months & \\
\hline No & 1 & \\
Yes & 0.61 (0.49 to 0.76) & 0.000
\end{tabular}

Exposure to HIV prevention service during the previous 6 months

\begin{tabular}{lll} 
No & 1 \\
Yes & $2.00(1.51$ to 2.64$)$ & 0.000 \\
\hline
\end{tabular}

FSWs, female sex workers; STI, sexually transmitted infection. engaging in safer sex, and self-efficacy is a strong indicator of self-reported consistent condom use by sex workers. ${ }^{1425}$ Moreover, older males were reported to have a higher prevalence of erectile dysfunction, hampering condom use. ${ }^{42}$ Consistent condom use during commercial sex is the most effective way to prevent transmission of HIV and STIs among FSWs. ${ }^{43}$ Therefore, it is necessary to inform low-tier FSWs of the risk of HIV/STIs, and the effectiveness of condoms for preventing unwanted pregnancy and HIV infection/STIs. Skills for negotiating condom use with clients, and for helping OMCs to use condoms, should also be promoted, to empower FSWs to use effective protection during commercial intercourse. Based on the results of this study, such interventions should be tailored specifically for low-tier FSWs engaged in sex with OMCs, because they see more clients with STIs or symptoms thereof, but show no increase in condom use or-self-efficacy compared with those who do not engage in sex with OMCs, even though they are more likely to be exposed to HIV prevention services.

The low-tier FSWs in this study who had commercial sex with OMCs were more susceptible to STIs than other low-tier FSWs. Also, they had more STI symptoms during the previous 6 months and were more likely to be diagnosed with an STI (among those who had seen a doctor). However, they were overall less likely to see a doctor during the previous 6 months. The univariate analyses showed that this group of FSWs was more likely to have higher awareness of the risk of HIV infection and STIs, but this association disappeared in the multivariate analysis. Education promoting risk awareness and knowledge of the consequences of STIs, along with the provision of treatment and referrals for STIs, should be promoted among low-tier FSWs, because $15.1 \%$ of those in our study reported STI symptoms during the previous half year and $27.5 \%$ reported having been diagnosed with an STI (among those who had seen a doctor).

Our study had several limitations. First, it used a crosssectional design, limiting the ability to make causal inferences regarding the relationships between the outcome and independent variables. Second, information biases, particularly those related to the sexual behaviour questions, may exist due to the sensitivity of sexual behaviour, the illegality and stigma of sex work in China, and social desirability. Third, the study was conducted over 3 months and used a non-random sampling method. These factors limit the generalisability of our findings to low-tier FSWs in other regions of China. Nevertheless, we believe that our sample is reasonably representative. This study was conducted in 21 counties among all 11 prefectures of Zhejiang province, and the participants were all low-tier FSWs working in various venues in these areas. The investigators were familiar both with local FSWs and their community; moreover, a pilot survey to confirm the locations of the low-tier FSWs was conducted, to ensure that all of the low-tier venues located by our investigators could be approached. Furthermore, the sample size was large. Finally, client ages were estimated 
by the participants, potentially reducing the reliability of this measure. However, considering the large number of clients and experience of the FSWs, their judgements of client age are generally considered credible. This also applies to the middle-aged and young clients seen during the previous month.

\section{CONCLUSIONS}

Our findings provide insight into the characteristics of low-tier FSWs engaging in commercial sex with OMCs. This group of FSWs are more likely to have risk factors for HIV infection/STIs compared with other low-tier FSWs, including a low educational level, a long duration of practising sex work, sex with more commercial clients, lower fees per sex act, anal or oral sex, current use of contraception, STI symptoms, and less likely to conduct sex with young clients and to have seen a doctor during the previous half year than those who did not have sex with OMCs. Future HIV/STI intervention programmes should take these characteristics into account, and special attention should be paid to low-tier FSWs. Also, free medical examinations and treatment should be included in such programmes given the low socioeconomic status of FSWs, and their low likelihood of seeing doctors and high prevalence of STIs. Interventions for the OMCs of low-tier FSWs should also be considered in these programmes, because they are also at high risk of HIV infection/STIs.

Acknowledgements The authors thank the outreach staff of the CDCs of Xiacheng District, Xiaoshan District, Fuyang City, Zhenhai District, Yinzhou District, Putuo District, Lucheng District, Xiuzhou District, Nanhu District, Deqing County, Anji County, Shangyu City, Shaoxing County, Yongkang City, Dongyang City, Wenling City, Shongyang County, Qingtian County, Yiwu City, Longyou County and Kecheng District, Zhejiang Province, for their contributions to the field work of this study. The authors also thank the FSW participants for their time and willingness to share information.

Contributors QM, JJ, TJ and XP analysed and interpretated the data, and drafted the manuscript. XP and JJ coordinated the study in the field; LC, HW, XZ and WC played a major role in the field survey. All authors contributed to the design of this study and read and approved the manuscript. QM and $\mathrm{JJ}$ are responsible for the overal content of this manuscript.

Funding The study areas were 21 counties in Zhejiang Province, where the AIDS Care Project, a programme supported by the National Ministry of Health and Zhejiang Provincial Bureau of Health to fund and promote HIV prevention policymaking, HIV-related education, behavioural interventions, counselling and testing, and antiretroviral treatments, was implemented. Our study formed part of this programme.

\section{Competing interests None declared.}

Patient and public involvement Patients and/or the public were not involved in the design, or conduct, or reporting, or dissemination plans of this research.

\section{Patient consent for publication Not applicable.}

Ethics approval This study received approval from the Ethics Committee of the National Centre for STD/AIDS Control and Prevention, China Centre for Disease Control and Prevention (X120331209; 31 March 2012). This study was also ratified by the Ethics Committee of Zhejiang Provincial Centre for Disease Control and Prevention. All potential participants were informed of the study's purpose and assured that their privacy and confidentiality would be protected. Participation in the study was voluntary, and verbal consent was obtained from all participants.

Provenance and peer review Not commissioned; externally peer reviewed.

Data availability statement Data are available on reasonable request. Data are available on reasonable request at qqma@cdc.zj.cn.
Open access This is an open access article distributed in accordance with the Creative Commons Attribution Non Commercial (CC BY-NC 4.0) license, which permits others to distribute, remix, adapt, build upon this work non-commercially, and license their derivative works on different terms, provided the original work is properly cited, appropriate credit is given, any changes made indicated, and the use is non-commercial. See: http://creativecommons.org/licenses/by-nc/4.0/.

\section{ORCID iDs}

Xiaohong Pan http://orcid.org/0000-0003-3373-3393

Qiaogin Ma http://orcid.org/0000-0002-8062-5697

Lin Chen http://orcid.org/0000-0003-2197-2733

\section{REFERENCES}

1 Baral S, Beyrer C, Muessig K, et al. Burden of HIV among female sex workers in low-income and middle-income countries: a systematic review and meta-analysis. Lancet Infect Dis 2012;12:538-49.

2 Shannon K, Crago A-L, Baral SD, et al. The global response and unmet actions for HIV and sex workers. Lancet 2018;392:698-710.

3 Huang ZJ, Wang W, Martin MC, et al. "Bridge population": sex workers or their clients?--STI prevalence and risk behaviors of clients of female sex workers in China. AIDS Care 2011;23(Suppl 1):45-53.

4 Kinsler JJ, Blas MM, Cabral A, et al. Understanding STI risk and condom use patterns by partner type among female sex workers in Peru. Open AIDS J 2014;8:17-20.

5 Zhang C, Li X, Hong Y, et al. Unprotected sex with their clients among low-paying female sex workers in Southwest China. AIDS Care 2013;25:503-6.

6 Chen Y, Shen Z, Morano JP, et al. Bridging the epidemic: a comprehensive analysis of prevalence and correlates of HIV, hepatitis $\mathrm{C}$, and syphilis, and infection among female sex workers in Guangxi Province, China. PLoS One 2015;10:e115311.

7 Zhou C, Hsieh E, Rou K, et al. Short-term acceptability of female condom use among low-fee female sex workers in China: a follow-up study. BMC Womens Health 2019;19:77.

8 Zhou C, Rou K, Dong WM, et al. High prevalence of HIV and syphilis and associated factors among low-fee female sex workers in mainland China: a cross-sectional study. BMC Infect Dis 2014;14:225.

9 Li J, Chen X-S, Merli MG, et al. Systematic differences in risk behaviors and syphilis prevalence across types of female sex workers: a preliminary study in Liuzhou, China. Sex Transm Dis 2012;39:195-200.

10 Zhang L, Chow EPF, Su S, et al. A systematic review and metaanalysis of the prevalence, trends, and geographical distribution of HIV among Chinese female sex workers (2000-2011): implications for preventing sexually transmitted HIV. Int J Infect Dis 2015;39:76-86.

11 Hong Y, Zhang C, Li X, et al. HIV testing behaviors among female sex workers in Southwest China. AIDS Behav 2012;16:44-52.

12 Chen B, Chen J, Shao Y, et al. Need for intervention services for promotion of condom use by female sex workers to consider size of entertainment venues: a cross-sectional study. Med Sci Monit Basic Res 2019;25:1-7.

13 Yang X, Xia G, Li X, et al. Social influence and individual risk factors of HIV unsafe sex among female entertainment workers in China. AIDS Educ Prev 2010;22:69-86.

14 Wang $\mathrm{H}$, Reilly $\mathrm{KH}$, Brown $\mathrm{K}$, et al. HIV incidence and associated risk factors among female sex workers in a high HIV-prevalence area of China. Sex Transm Dis 2012;39:835-41.

15 Lu F, Jia Y, Sun X, et al. Prevalence of HIV infection and predictors for syphilis infection among female sex workers in southern China. Southeast Asian J Trop Med Public Health 2009;40:263-72.

16 Chen X-S, Liang G-J, Wang Q-Q, et al. HIV prevalence varies between female sex workers from different types of venues in southern China. Sex Transm Dis 2012;39:868-70.

17 Wu J, Zhang Y, Shen Y, et al. Phylogenetic analysis highlights the role of older people in the transmission of HIV-1 in Fuyang, Anhui Province, China. BMC Infect Dis 2019;19:562.

18 Haddad N, Robert A, Popovic N, et al. Newly diagnosed cases of HIV in those aged 50 years and older and those less than 50: 2008-2017. Can Commun Dis Rep 2019;45:283-8.

19 National Center for AIDS/STD Control and Prevention China CDC. National HIV/syphilis/HCV sentinel surveillance report in 2016. Beijing 2016.

20 Jiang GJ, Wu GH, Pei YX. Current status of HIV infection and research progress on behavioral characteristics among elderly people in China. Practice Preventive Medicine 2019:510-3.

21 Zhejiang provincial center for disease prevention and control. Letter on reporting results of HIV epidemic assessment in Zhejiang Province. Hangzhou 2019. 
22 Huang Y, Maman S, Pan S. Understanding the diversity of male clients of sex workers in China and the implications for HIV prevention programmes. Glob Public Health 2012;7:509-21.

$23 \mathrm{Lu} \mathrm{H}$, Zhu Y, Wu X, et al. [Study on the characteristics of commercial sexual behavior and the risk factors analysis of HIV infection among the old male clients, in Guangxi]. Zhonghua Liu Xing Bing Xue Za Zhi 2015;36:31-4.

24 Chen Y, Tang Z-zhu, Shen Z-yong, et al. [Investigation on the risk factors for HIV infection among elderly male clients of the commercial female sex-workers in Guangxi Zhuang Autonomous Region, in 2012]. Zhonghua Liu Xing Bing Xue Za Zhi 2013;34:1086-90.

$25 \mathrm{Ma} \mathrm{Q}$, Jiang J, Pan X, et al. Consistent condom use and its correlates among female sex workers at hair salons: a cross-sectional study in Zhejiang Province, China. BMC Public Health 2017;17:910.

26 Hong Y, Zhang C, Li X, et al. HIV testing behaviors among female sex workers in Southwest China. AIDS Behav 2012;16:44-52.

27 Hao C, Liu H, Sherman SG, et al. Typology of older female sex workers and sexual risk for HIV infection in China: a qualitative study. Cult Health Sex 2014;16:47-60.

28 Nasirian M, Kianersi S, Hoseini SG, et al. Prevalence of sexually transmitted infections and their risk factors among female sex workers in Isfahan, Iran: a cross-sectional study. J Int Assoc Provid AIDS Care 2017;16:608-14.

29 Simonsen JN, Plummer FA, Ngugi EN, et al. HIV infection among lower socioeconomic strata prostitutes in Nairobi. AIDS 1990;4:139-44.

30 Choi SYP, Holroyd E. The influence of power, poverty and agency in the negotiation of condom use for female sex workers in mainland China. Cult Health Sex 2007;9:489-503.

31 Liu Q, Zhuang K, Henderson GE, et al. The organization of sex work in low- and high-priced venues with a focus on the experiences of ethnic minority women working in these venues. AIDS Behav 2014;18 Suppl 2:172-80.

32 Chen Y, Abraham Bussell S, Shen Z, et al. Declining inconsistent condom use but increasing HIV and syphilis prevalence among older male clients of female sex workers: analysis from sentinel surveillance sites (2010-2015), Guangxi, China. Medicine 2016;95:e3726

$33 \mathrm{Li} \mathrm{Y}$, Detels R, Lin P, et al. Difference in risk behaviors and STD prevalence between street-based and establishment-based FSWs in Guangdong Province, China. AIDS Behav 2012;16:943-51.

34 Patel P, Borkowf CB, Brooks JT, et al. Estimating per-act HIV transmission risk: a systematic review. AIDS 2014;28:1509-19.

35 Boily M-C, Baggaley RF, Wang L, et al. Heterosexual risk of HIV-1 infection per sexual act: systematic review and meta-analysis of observational studies. Lancet Infect Dis 2009;9:118-29.

36 Longo JDD, Simaleko MM, Diemer HS-C, et al. Risk factors for HIV infection among female sex workers in Bangui, central African Republic. PLoS One 2017;12:e18765

37 Mazeingia YT, Olijijira L, Dessie Y. Anal sexual experience and HIV risk awareness among female sex workers in dire Dawa, eastern Ethiopia. Glob Health Res Policy 2017;2.

$38 \mathrm{Ma}$ Q, Pan X, Cai G, et al. The characteristics of heterosexual STD clinic attendees who practice oral sex in Zhejiang Province, China. PLoS One 2013;8:e67092.

39 Chen WY, Pan XH, Guo ZH, et al. [Analysis of oral sexual behavior and related factors among male students from college graduation in Hangzhou]. Zhonghua Yu Fang Yi Xue Za Zhi 2019;53:289-92.

40 Lim MSC, Zhang X-D, Kennedy E, et al. Sexual and reproductive health knowledge, contraception uptake, and factors associated with unmet need for modern contraception among adolescent female sex workers in China. PLoS One 2015;10:e115435.

41 Zeng H, Zhao Y, Meng S, et al. Exploring HIV prevention strategies among street-based female sex workers in Chongqing, China. Int $J$ Environ Res Public Health 2015;12:855-70.

42 Corona G, Lee DM, Forti G, et al. Age-related changes in general and sexual health in middle-aged and older men: results from the European male ageing study (EMAS). J Sex Med 2010;7:1362-80.

43 Lai J, Qin C, Nehl EJ, et al. HIV prevalence among female sex workers in Guigang City, Guangxi, China: an 8-year consecutive cross-sectional study. BMC Public Health 2018;18:450. 